\&c., \&c., homœopathic surgeon, surgeon to his own homoepathic dispensary.

On Sunday evening, at the night visit of Mr. Harris, finding his medicine untouched, the cold lotion discontinued, the warm fomentations laid aside, and the injections obstinately refused, he begged to know the reason of such neglect, and was informed that the other doctor had been to see her, and had told her to take nothing but what he gave, to submit to no operation, to go to no hospital, to do nothing but what he advised, and, by the blessing of God on his means, he would cure her without cutting her about. My friend remonstrated, and pointed out the folly of the advice and the danger of delay; for, prior to the other doctor's visit, and since Mr. Harris's mid-day attendance, the matter vomited had become stercoraceous.

The promise of cure without cutting, coupled with the religious hope of "God's special blessing on his means," had produced their full effect on the poor woman's mind, and she firmly believed she was to recover under the care of the homcopathist, who, she exultingly told Mr. Harris, had "given her some of the most wonderful medicine she ever saw in her life."

On Monday morning $I$ again saw her, and repeated my warning as to consequences, and the futility of all medicines as means of cure; but finding her firmly under the same influence as on the preceding evening, I discharged myself from all further responsibility, pointing out to her, that as she preferred other advisers, they were wholly responsible for both the nature and effects of their advice. The progress of her case was most carefully watched by Mr. Harris, who repeatedly saw her, in the hope of still serving her. The bowels were never relieved; she existed eight days in the most miserable state of almost constant frecal vomiting, during the whole of which time she swallowed the globules, and was told, in opposition to her own feelings, that she was going on favourably, and that the tumour was getting smaller; and she also expressed herself satisfied that the gentleman would cure her, as he had promised. On the ninth day of the globular system of hernial treatment, the homoopathic "sort of a doctor" becoming alarmed at the increasing urgency of his patient's danger, and the heavy responsibility of his own position, endeavoured to persuade the poor woman that even he was beginning to think an operation advisable. On the following day, (Tuesday, Sept. 29th, he summoned to his consultation two other homcopathists, to outweigh the effect of his promise to cure "her without cutting her about," and the subsequent week's schooling against the necessity of an operation. From that time, the poor woman told Mr. Harris, her fate was doomed; she had been deceived, and had lost all hope from medicine, or faith in doctors. She would not consent to an operation, and died on the night of the 30 th. She assured iny friend, on the day before her death, that had all the doctors agreed at first as to the necessity of the operation, she would have submitted; but that when he, the homoeopathic doctor, turned round and advised what he had said all along was unnecessary, her heart failed her, and she could not bear to be further pressed on the subject.

An inquest was held on the body, and a post-mortem examination made. The disease was never doubted, and inspection proved that she died from the effects of an unrelieved oblique inguinal hernia.

The practitioner of homcopathy was present at the examination of her dead body, and consoled himself over it with the disgusting self-laudation, that by his treatment he had preserved her life for ten days, from Sunday to the Wednesday week. How passed? In the continued misery of almost constant stercoraceous vomiting !

How, Sir, are we to desirnate such conduct? What can be said of the state of a man's mind, that can extract self-commendation from such a course, as first to withdraw this poor woman's confidence in legitimate surgical art, then proceed to mislead her, by the show of inert worthless medicinal remedies, and afterwards, at the remotest possible moment of delay, veer round, and urge her back on the path he had been warning her against-thus confessing his own imposture; and after the effects of uncontrolled disease had worked their end, could console his conscience with the charming reflection, that his charms had been working well for ten long, lingering days!

The deceiver always laughs at his dupe; and in this instance the rictim of misplaced confidence was, after her death, accused of obstinacy by this expositor of the mysteries of homoopathy, for adhering to the advice given by himself longer than it suited his purpose, or his humour.

The practitioner of homoeopathy is not in this, or any similar case, to be restrained by any legal penalty, for none attaches; he did no act technically moving to her death, for the administration of homoopathic globules is an act but moving to the fancy; his practice lay in no errors of commission, for homœopathic globules are too inert to commit any but deeds of wonder. But the error lies deeply in deeds of omission, in not doing what ought to be done, in not advising as knowledge and experience dictate. If, then, no legal penalties attach to such practices in similar cases, ought not the higher moral censure to attach to the individual who, imposing himself on another, as a qualified adviser, in moments of imminent danger, takes upon himself the responsibilities of life and death, and then, laying aside all ascertained means of safety to his patients, directs them along the untrodden path of some new fancy, possessing not even the semblance of truth or reason for its recommendation?

Union-place, City-road, October, $18+6$.

\section{ON ELECTRICITY,}

$$
\text { CONSIDERED AS A }
$$

\section{PHYSIOLOGICAL \& HEAT-PRODUCING AGENT,}

THE PURPOSES ANSWERED BY FOOD TAKEN IXTO THE SYSTEM, AND THE REFRIGERATING INFLUENCE OF RESPIRATION.

\section{By J. W. LAKE, Esq., Holbeach.}

As the theory of animal temperature still remains one of those points in physiology not yet clearly demonstrated, the following suggestions, explanatory of this phenomenon, may not prove unacceptable.

A long course of observation has enabled me to arrire at the conclusion that every operation of Nature, both in the organic and inorganic kingdoms, is occasioned, either directly or indirectly, by that power or agent already known to us under the term electricity; that this subtle principle acts, as it were, as the link connecting these functions with the fiat of the Creator. Taking this enlarged view of that mys terious power which

"Lives through all life, extends through all extent Spreads undivided, operates unspent."-POPE.

I have, by identifying it with heat in the inorganic kingdom, been enabled to throw some additional light on many of the physiological functions. But for the identification: Sir David Brewster has proved to us that there are, in the northern hemisphere, two poles of extreme cold, and that these poles are also the magnetic poles or spots at which the needle assumes a perpendicular position. He has shown, also, that lines drawn equidistant round these poles, are isothermal, or lines of equal temperature. Again: the magnetic equator does not correspond with the terrestrial equator, and the isothermal line follows the course, not of the terrestrial but of the magnetic equator. Who then can doubt the intimate relation existing between heat and electricity? and if, coupled with this, we regard the sun as the source of both, we have the conviction of their identity still deeper impressed within us. But more than this, Derbeck has shown us how to convert heat into electricity; and Peltier has taught us how to convert electricity into heat. What more than such proofs can be wanting to convince the most sceptical that heat and electricity are one and the same agent? And if we are at present unable to determine the exact laws which gorern its access in these varied states, it is a proof, not that these laws do not actually exist, but rather, that our ignorance and misdirected research have hitherto been a barrier to their discovery. Still, however, as it is of the highest importance to the stability of the theory I am about to propose, that this identity should be completely and undeniably established, I will further trespass upon attention to add what I might almost term a mathematical proof of the fact. For instance: let us take a pound of water at the ordinary temperature of the atmosphere; by the passage of a stream of electricity this water is converted into a certain bulk of the mixed gases, which we must represent by water, the electricity consumed in its transtormation. If we combine these gases so as again to form water, we find no trace of electricity given off, but their reunion is accompanied by an intense decrree of heat. Now, as heat and electricity are finite agents, which can neither be created nor destrored, the questions to be solved are-Where lras the electricity gone to? Where did the heat come from? It is clear that the electricity absorbed in the decomposition of the water has been again given ont as heat on the reunion of the gases; in short, we have it as an established fact that electricity and heat are identical. Fow it is 
by a conversion of electricity into heat that $I$ intend to account for the phenomenon of animal temperature, and it will therefore be necessary for me first to show that the body is continually receiving a supply of that agent.

It is an admitted fact in plysiology, that the particles which form our bodies are continually undergoing a change; and although the softer portions are more frequently renewed than bone and cartilage, yet an attempt has been made to fix the average length of time required for such change to be effected, and at a low calculation seven years is the time fixed uponthat is, it is computed that in seren years we shall, by means of the nourisliment derived from our food, have formed an entirely new body. But during that period, we shall have consumed, on a low calculation, between 4000 and 5000 pounds of solid food. Now the arerage weight of a man, including fluids, is 150 pounds, and yet, to form a new body, he must consume nearly a couple of tuns of solid food, exchusive of liquids, every particle of which is capable of being converted into animal fabric. It is evident, then, that while food serves to nourish our frame there must be some other great purpose answered by it, or Nature must have been very remiss in her workmanship. The size, too, of the thoracic duct, the channel by which nutriment is received into the system, bears a very small proportion to the bulk of food necessary to appease the sensations of hunger. It is clear, then, that while nutrition is a very necessary function, it is yet only secondary to some other great end which the bulk of food is destined to answer. For if we refuse to admit this mode of argument, if we consider nutrition as the only service derivable from food, and then see, as is above shown, that a man must take thirty ounces of food to supply one ounce of waste-do we not perceive at once a great apparent departnre of Nature from the admirable and economic system in which all her operations are conducted? Are we not compelled to exclaim, with the poet-

\section{"Reasoning, I oft admire}

How Nature, wise and frugal, could commit

Such disproportions."-MILTON.

Now as electricity is elicited by chemical decomposition and as chemical decomposition of the food occurs immediately it is received into the stomach, in the process called digestion, there is every reason to suppose that the purpose which a bulk of food is destined to serve, is, to afford by its decomposition a sufficient supply of animal electricity; and this seems to be, in a great measure, borne out by observation. Food is very variable in its nature. Spirits afford a large amount of heat while burning-a proof that their chemical decomposition in the stomach affords a large amount of electricity. Meat and all kinds of stimulating and animal food afford a much greater supply of this agent than does a bread or vegetable diet. Hence we find that a great drinker is but a little eater; and why? He supplies a sufficiency of electricity from spirituous liquors, and he therefore only requires a small amount of solid food to answer the purposes of nutrition. A person living on a good supply of animal food requires much less bulk than those compelled to subsist wholly on vegetable diet. The bulk of a good meat meal is very disproportionate to the mess of oatmeal porridge consumed by the Highlander, or the potato diet of the Irishman. Food, then, is intended to serve the great purpose of keeping alive the vital spark, by supplying the subtile agent on which its existence depends; and this carries with it the conviction, that it is the electricity thus eliminated that constitutes the nervous ageut, and that it is a diminution of this subtile principle in our system that occasions the sensation of hunger; for we cannot suppose for a moment that this monition arises from any wasting of the body requiring reparation, whilst the languor and debility occasioned 'by abstinence, and the soul-reviving invigoration produced by refreshment, elearly point out that muscular debility, and not muscular diminution, was the canse of hunger, and that it was a fresh supply of animal spirits, and not animal fabric, that was needed.

We lave the stomach, then, as the laboratory in which the vital agent is eliminated, and we must view the brain, not with Dr. Arnott, in the light of a galvanic battery, but merely as a receptacle or reservoir, in which this agent is received, and from which it is dispensed-- the par vagum, or pneumogastric nerves, being the medium of communication. This view will readily explain to us why a state of collapse, or deficiency of nervous agency, should be occasioned by a blow upon the stomach, as also the unpleasant sensations, termed heidach, produced in the brain, when, by means of spirits or High-seasoned food received into the stomach, too great a quantity of the vital agent has been directed to it. Now, with regard to animal temperature, space will not permit me to allude individually to the various theories which have been put forward explanatory of this phenomenon; but classing them as those which refer the source of heat to the changes occurring in the lungs during respiration, and as those which refer it to the contractions and dilatations of the heart and arteries, I will briefly endeavour to prove their fallacy.

Respiration is essentially a cooling process. Witness the respiration of a dog, who perspires almost solely by the tongue, and whose quick panting respiration is the chief means of cooling its overheated body. I do not for a moment deny that the decarbonizaiion of the blood is attended by an evolution of heat; but I assert that the heat thus produced is insufficient even to raise the bulk of air inspired from the iemperature of the atmosphere to that of the lungs, and as the expired air is of a temperature equal to that of the body, it follows that at every expiration heat must be carried off, and that the process, so far from imparting heat, is one of the means by which the cooling of our bodies is effected. Another class of theorists suppose, with Dr. Winn, that the alternate contractions and dilatations of the heart's arteries prove an efficient source of animal temperature, in the same manner as that a piece of caoutchouc becomes heated when suddenly stretched. But are these theorists aware that lieat is a finite agent, and must lave a source? That if this contraction and dilatation produced heat, in the absence of any chemical change taking place in the parts themselves, this heat must be derived from the surrounding parts, and therefore this process, while it might, perhaps, elicit heat, could not in any way be considered as its generator.

The only theory worthy of consideration is that proposed by that eminent physiologist, Sir Benjamin Brodie, whose experiments have clearly proved that animal temperature is depend. ent entirely upon the nervous system. But increased nervons excitement is attended not only with increased temperature, but also with increased circulation and increased respiration; and this accounts for the error into which so many have fallen in searching for the cause in these latter functions. Assuming, then, electricity to be identical with the nervous agent, the following I conceive to be the modus operandi of its heat-producing properties:-We find throughout the system that the necessary apparatus for carrying on organic life consists in a vein, an artery, and a nerve. The nerve conveying the peculiar principle of vitality exerts a decomposing property, and effects a decomposition of the parts to which it is directed, the results of which are taken up by the veins, which here act the part of scavengers of the body, while the arteries furnish fresh matter to be converted into animal fabric; and it is the chemical combinations which here take place that prove the efficient source of animal heat. This $I$ consider to be the modus operandi of the healthy state. Now the production of heat in fever appears to arise from a different source, and I should conceive it to be in great measure dependent upon the immediate conversion of the nervous agent into heat, arising from the nerves being too highly charged, in the same wry that a wire becomes red hot if it be insufficient to conduct the amount of electricity attempted to be passed along it. But then the question arises-Where does the electricity originally come from? In fevers no food is taken. Though in the healthy state the stomach is the chief source of supply, still there are other channels by which this agent can be received into the system-the pointed fibres of the hair, for instance, thus explaining the good effects resulting from shaving the head, and insulating it by an oilskin cap, with the use of evaporating lotions, which all prove such serviceable remedies in the severer forms of febrile affections.

Now if nervous influence be the sonrce of heat, mental emotions, which produce such sudden changes in the nervoussystem, should also exert an influence over the temperature of the body, and we find that a sudden flush or a death-like chilliness are the effects of the exciting or depressing passions. For instance, in the case of extreme fright there is generally a loss of heat, accompanied with contractions of the muscles, and a bristling sensation of the hair. Painters in depicting this emotion, have invariably done so by these characteristics; and Shakspeare, one of the greatest observers and analyzers of man that has appeared, especially alludes to them.

"I could a tale unfold, whose lightest word Would harrow up thy soul ; freeze thy young blood And make

Each individual hair to stand on end,

like quils upon the fi etful porcupine."

Now, in this bristling sensation, the veriest tyro in electrical science cannot fail to observe an electrical phenomenon-the escape of electricity by the pointed fibres of the hair, whilst the loss of heat indicates the loss of electricity, and the con- 
traction of the muscles indicates its passage. This, too, affords a convincing proof that the mental and physical agents are the same. Here mental emotion produces physical disturbance; in that physical disturbance we recognise electricity, and therefore we conclude that this agent is productive alike of our mental and corporeal faculties; that the human mind is mysteriously connected with it; in short, that electricity is the vital principle. That electricity is the vital agent is an idea by no means new or original; but the causes which have prevented a more clear demonstration of the fact have been the limited views which philosophers have taken of this mighty agent. The snap and the spark have been too much regarded as the sole test of its presence, and therefore while they have recognised it in the rolling thunder and withering lightning of the tempest, they have failed to discern it in the secret power that governs the reins of the whirlwind, or in its milder character, as the instrumental means of tempering and regulating climate, and as producing, by its varied action, all that is delightful, mournful, or terrible in Nature. They have traced it as the silent agent, which, deep in the bowels of the earth, is productive of mineral formation; but they have forgotten to follow its workings through the various grades of vegetable and animal life, till they should arrive at the crowning feature of creative skill-man.

$$
\begin{aligned}
& \text { " Connexion exquisite of distant worlds! } \\
& \text { Distinguish'd link in being's endless chain! } \\
& \text { Midway from nothing to the Deity" - Youv }
\end{aligned}
$$

To study man aright, he must be considered, not as a machine, complete and perfect in itself, but as a being con. nected with external objects, and influenced by external causes; as a part, in short, of that creation, of which it is happily said, that

\section{Inspires, and feeds, and animates the whole."-DRYDEN.}

This is the view which a philosopher must take of creation before he can comprehend its mysteries; this is the only means by which he will be enabled to penetrate into the secret recesses of Nature; and although the possession of the Promethean fire must ever be ranked with the impossibilities of the elixir vitæ and philosopher's stone, yet Nature, viewed in this light, will open up to us new themes for our admiration, new wonders for our amazement, and as the great scheme of creation becomes more unfolded to our view, we shall exclaim, in the impassioned language of Byron,

"Are not the mountains, waves, and skies, a part

Of me, and of my soul, as I of them ?"

Holbeach, Oct. 1846

\section{ON ELEPHANTIASIS,}

\section{ITS HISTORY AND TREATMENT.}

\section{By HENRY G. DALTON, Esq., M.R.C.S. Eng., Georgetown,} Demerara.

ThE term elephantiasis (elephant leg) has been applied to the designation of one of the most formidable and inveterate diseases that mankind has experienced-formidable as regards its revolting aspect, and inveterate as concerning the difficulty hitherto met with in its alleviation, much less cure.

Of its antiquity there can be no doubt, as will be demonstrated by the remarks of some of the oldest writers on medicine. From the earliest period up to the present time, it has been considered as an "opprobrium artis medicæ," since it has baffled the skill of the most scientific, and wearied the patience of the most industrious inquirers, who have sought to investigate its nature. But, as has often been remarked in the history of medicine, in reference to other diseases, the gradual accumulation of facts concerning it has eventually done much towards facilitating our present knowledge of the disease; and the various hints and suggestions thrown out regarding the possibility of a cure having been tested by experience, now render almost certain the means of effectually relieving the disease. It must not be overlooked, that in almost every age native remedies have been started in every quarter where this disease is prevalent, each warranting a cure; and it is not to be doubted that solitary cases of recovery have been now and then met with.

In making use of the term elephantiasis, as applicable to the disease under consideration, we must take care not to confound it (as has been frequently done) with another disease totally different, known by the same appellation; and for this purpose we will give its synonymes.

Two diseases have been designated by the term elephantiasis,-one, "elephantiasis Græecorum," a special disease of the skin, usually attacking the face and ears, called also,
" tubercular elephantiasis," "leontiasis," (and "juzam" by the Arabian writers,) this being essentially a contagious disease. The other, "elephantiasis Arabica," is the distinctive name of the subject of the present essay; but it has received various appellations from almost every writer on the subject. Dr. Mason Good has termed it, "Bucnemia Tropica," and classes it under "Phlegmasia," taking a riew of its inflammatory nature. By the Arabian physicians it was termed "dal til," which signifies elephant leg. "Dr. Hillary calls it "Barbadoes leg;" Dr. Hendy, the glandular disease of Barbadoes. By some it has been called "yam leg," from its resemblance to the vegetable of that name, and the term, as a popular one, is correct enough. In Ceylon it is termed " galle leg." In the Polynesian isles it has received the name of "yava skin," from its supposed origin from a drink so called. In Malabar it is called "kaal," which also signifies elephant leg. By French writers it has been termed "andrum," "sarcocele d'Egypte," "æolica Japonica," "lepra elephantiasis," "lepra tuberculeuse elephantine;" by Alibert, "elephantiasis tubereux;" by Kampfer it was styled "pedarthrocace." On the peninsula of India it is known as "Cochin leg."

The disease thus varionsly denominated is not contagious; but it is endemic, and seems to depend upon certain conditions of the system and of climate, which must be hereafter considered.

The first description of the disease was given by Rhages, the Arabian physician, who lived in the year 850 A.D. From him it received the name, "elephas Arabus," or " dal til," and it is remarkable that his description accurately represents it as at present met with, and, moreover, that one of the chief elements in its cure should have also been suggested at that time. From this period numerons writers have given descriptions of the disorder, amongst others, Dionis, Cheselden, Walther, Morgagni, Chopart, and Larrey. It has been generally remarked by all these writers, that the disease, though endemic, chiefly attacks persons either born or long resident in certain places, as Barbadoes, Malabar, Egypt, Ceylon, \&c.

It chiefly attacks the lower classes of these inhabitants, and the dark races of mankind are more liable to it than the fair. Thus, in Barbadoes it was confined to the black population until 1700 , from which period, however, to the present time, numerous instances of its attacking white people have been encountered. Persons liable to it in one locality have been known to remain free from its invidious ravages on quitting for other countries. It has rarely been known to attack soldiers, and others who migrate.

Individuals coming to live in a country where this disease is prevalent do not become attacked at an early period of their residence; it seems to require a certain amount of "seasoning," in order to render the constitution liable to its influence. It equally affects both sexes; but the young seem more subject to its contamination than those more advanced in life. It rarely breaks out in an old person who had not previously had some premonitory symptoms in early life. Instances of infants being attacked by elephantiasis Arabica have been met with, although rarely. It would seem that the brute creation is not free from its baneful influence, since it has been asserted that horses, dogs, ponltry, and other animals, have been subjects of it.

In Polynesia, this frightful affection is regarded, like the gout in Europe, in rather an honourable light, inasmuch as it is considered an indication of high living, and to be chiefly induced by the use of a certain intoxicating beverage, called "vava." It is not, however, confined to the higher classes in this region. The disease has been chiefly, if not altogether, confined to warm latitudes. Dr. Titlev, who wrote on the genito-urinary organs, has remarked, that in the Orkney Isles cases have appeared; still its remote and exciting causes are, for the most part, found in warm latitudes, and where malaria is prevalent. In some countries, as British Guiana, the aboriginal inhabitants are not subject to it; but this may, in some measure, be accounted for br the tact that the climate of the interior of this country, where the aborigines chiefly reside, is of a very difierent character to that inhabited by the other settlers, the former region being generally high land; the latter marsiy, low, and bordering on mouths of rivers and the sea. It has, in this respect, much analogy with intermittent ferer, with which it is trequently associated.

Having thus briefly skstched some prominent facts connected with the disease, it will be now necessary to give some description of its appearance, and the parts of the body that are liable, or have been known, to be attacked by it.

Elephantiasis Arabica consists of a marked enlargement of the limb, (or parts affected, with thickening of the integument and the subjacent cellular tissue, rarying degrees 